\title{
Cambios y permanencias en torno al proceso de dispersión agrícola en las Sierras Centrales de Argentina
}

\author{
Sebastián PASTOR y Eduardo BERBERIÁN \\ CONICET/Centro de Estudios Históricos «Prof. Carlos S. A. Segreti» \\ pastorvcp@yahoo.com.ar; eduardoberberian@hotmail.com
}

Recibido: 19 de marzo de 2014

Aceptado: 28 de mayo de 2014

\begin{abstract}
RESUMEN
En esta contribución se realiza una síntesis e integración de los datos arqueológicos disponibles sobre el proceso de dispersión agrícola en la región central de Argentina durante el Holoceno Tardío. En oposición a las visiones más extendidas, que pusieron énfasis en los cambios presuntamente asociados a la adopción de la agricultura, se sostiene el carácter limitado de la producción agrícola y sus consecuencias, así como las fuertes continuidades con el pasado. Se observa una introducción lenta y gradual de vegetales domesticados como el maíz ( $c a$. 3000-2500 AP), probablemente obtenidos por los cazadores-recolectores locales a través de intercambios con vecinos agricultores. También se registra una incorporación paulatina de tecnologías como la cerámica. La introducción de cultivos de pequeña escala y otras innovaciones en un momento tardío del período prehispánico, $c a$. 1000-900 AP, fueron integradas a lógicas culturales y modos de vida tradicionales, en la búsqueda de su conservación, a pesar de que a largo plazo se produjeran transformaciones más o menos profundas por la acumulación de cambios interrelacionados.
\end{abstract}

Palabras clave: Transición agrícola, maíz, cambio social, caza-recolección.

\section{Changes and Stays Around the Agricultural Dispersion Process in the Central Hills of Argentina}

\begin{abstract}
A synthesis and integration of archaeological data on the process of agricultural dispersal in the central region of Argentina during the Late Holocene is performed. In contrast to the more widespread visions that emphasized changes allegedly associated with the adoption of agriculture, the limited nature of agricultural production and its consequences is affirmed, as well as strong continuities with the past. Slow and gradual introduction of domesticated plants like maize (c. 3000-2500 BP), probably obtained by local foragers through exchanges with neighboring farmers is observed. Gradual incorporation of technologies like ceramic is also registered. The introduction of small-scale crops and other innovations in a late stage of the Pre-hispanic Period, $c$. 1000-900 BP, were integrated into cultural logic and way of life in the pursuit of its conservation. However long-term more or less profound transformations were produced by the accumulation of interrelated changes.
\end{abstract}

Key words: Agricultural transition, maize, social change, hunting and gathering.

Sumario: 1. Introducción. 2. Etapas iniciales del proceso. 3. La adopción de los cultivos. 4. Producción agrícola, procesos económicos y cambio social. 5. Consideraciones finales. 6. Referencias bibliográficas.

\section{Introducción}

Ubicadas en el centro del actual territorio argentino, las Sierras de Córdoba y San Luis comenzaron a ser exploradas y colonizadas desde la transición PleistocenoHoloceno, ca. 11 000-9000 AP (Figura 1). Desde esos comienzos hasta el Holoceno Tardío final, a lo largo de varios milenios, se produjo un extenso proceso de desarrollo y transformación de las sociedades de cazadores-recolectores (Rivero y Berberián 


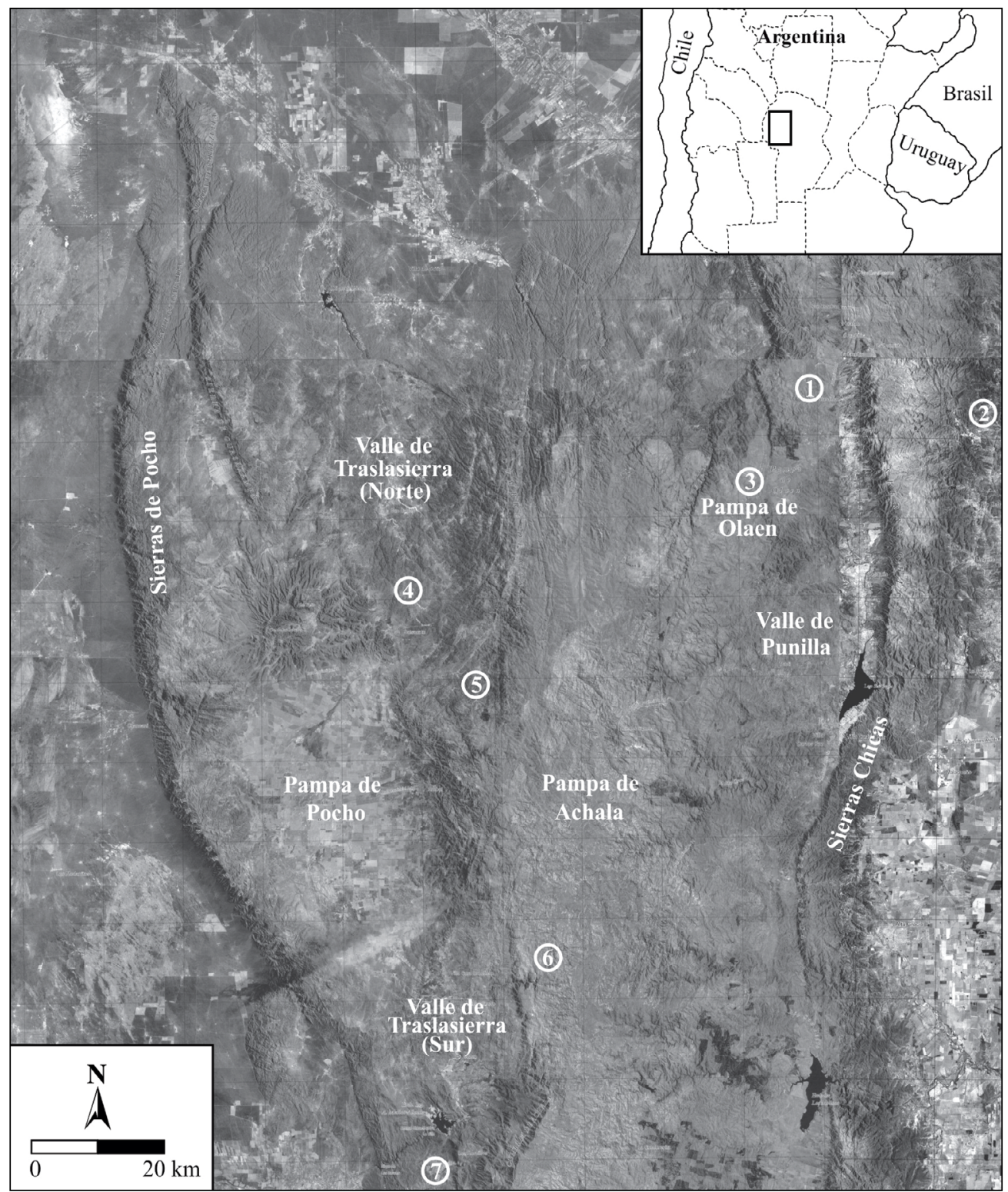

Figura 1: La región de estudio en el sector central de las Sierras de Córdoba (Argentina) y localización de los sitios mencionados en el texto. (1: C.Pun.39; 2: Agua de Oro; 3: Puesto La Esquina 1; 4: Cruz Chiquita 3; 5: Arroyo Tala Cañada 1; 6: Quebrada del Real 1; 7: Guasmara).

2008). Uno de los hitos más significativos habría sido la transición hacia una economía de base agrícola, adoptada en algún momento del Holoceno Tardío. De este modo, el proceso de dispersión de la agricultura andina habría alcanzado uno de sus límites, específicamente el sudoriental (González y Pérez 1972). 
Más allá de los matices entre diferentes investigadores, existió un cierto consenso en definir a esta innovación como un quiebre en la trayectoria histórica local. La adopción de cultivos debió promover o acompañar a una serie de cambios en el modo de vida, la tecnología, la economía (con un énfasis productivo agrícola e incluso posiblemente el pastoreo de camélidos), en las pautas de asentamiento y movilidad (con un mayor sedentarismo), así como en la organización social (Berberián 1984, 1999; González y Pérez 1972; Laguens y Bonnín 2009). En efecto, con el advenimiento de una «etapa agroalfarera» $\mathrm{o}$ «productora de alimentos» se habría superado una prolongada «etapa precerámica», de plena caza y recolección.

La reconstrucción de estos procesos estuvo apoyada en una información arqueológica escasa e indirecta, así como en diversos supuestos a priori sin una contrastación empírica posterior (por ejemplo la asociación cultivos-alfarería-sedentarismo). La escasa conservación de restos vegetales, el limitado desarrollo de la arqueobotánica, así como la inexistencia de una infraestructura productiva prehispánica de alta visibilidad (andenes, terrazas, cuadros de cultivo), revirtieron en un escaso tratamiento del problema con metodologías arqueológicas y en su lugar, el empleo de los datos contenidos en las fuentes históricas del siglo XVI. Estos documentos aluden a las «sementeras» $\mathrm{y}$ «chacaras» donde los indígenas del tiempo de la conquista sembraban maíz (Zea mays), zapallos (Cucurbita sp.), «frijoles» (Phaseolus spp.), «camote» (posiblemente Ipomoea batatas) y quínoa (Chenopodium quinoa) (Berberián 1987). Desde esta postura, a partir de un foco colocado en el supuesto peso de las transformaciones, las numerosas permanencias con el pasado cazador-recolector se vieron marginadas. Se aceptó el mantenimiento de las prácticas extractivas tras la introducción de los cultivos, pero éstas se habrían redefinido como un complemento de la producción agrícola.

Además de los puntos de acuerdo, existieron matices y contrastes en la conceptualización de diferentes aspectos del proceso. Para algunos autores la expansión de la agricultura acompañó el desplazamiento, presumiblemente desde Santiago del Estero, de grupos agricultores que comenzaron a asentarse en la región (González y Pérez 1972; Montes 2008). En otros casos se puso el acento en el proceso local de transformación de los grupos cazadores-recolectores (Berberián 1999; Laguens y Bonnín 2009).

Se plantearon nociones disímiles acerca de las características intrínsecas del sistema productivo. Para Laguens (1999) debió tratarse de una producción «máxima y óptima», con aprovechamiento de la totalidad de terrenos cultivables, en tanto que para González y Pérez (1972), así como para Montes (2008), habría sido común el empleo de regadíos. Por nuestra parte nos aproximamos a la definición de una producción de pequeña escala, de tipo horticultura, complementaria de la caza-recolección, mínimamente tecnificada, de secano y en base al cultivo de distintas especies y variedades (policultivo) (Medina et al. 2014; Pastor y López 2010).

Muchos de estos problemas e interrogantes son aun escasamente conocidos, dadas las limitaciones de la información. A pesar de ello, en los últimos años se han logrado avances a partir de la investigación sobre diferentes líneas convergentes. Estas comprenden desde arqueobotánica e isótopos estables, hasta arqueología de variados paisajes y tipos de asentamientos (residenciales, agrícolas, ceremoniales, refugios 
transitorios, etc.) (Laguens et al. 2009; Medina et al. 2009; Medina et al. 2014; Pastor y Berberián 2007; Pastor y López 2010; Pastor et al. 2012; Recalde 2014; Rivero et al. 2008-09).

Más allá de sus límites los resultados permiten plantear, cuanto menos, la necesidad de continuar con un calendario de investigación que sitúe el problema en otro punto de partida, uno que intente aprehender la complejidad y singularidad del proceso, tanto como sus conexiones externas, logrando una mayor contextualización y eventualmente, la proyección de las tendencias y patrones identificados.

El planteamiento de este trabajo se asienta sobre dos nociones básicas. Primero, que la transición agrícola en la región, o dicho en otros términos, el proceso que condujo a una creciente interacción entre personas y vegetales domesticados, incluyendo prácticas de cultivo, no se produjo en forma rápida y por una adquisición «automática» por parte de las diferentes comunidades. Por el contrario, habría sido un proceso lento, no unidireccional, que permitió a lo largo de un extenso período el acceso a este tipo de recursos por parte de los cazadores-recolectores, a través de mecanismos de intercambio y sin la implementación efectiva de cultivos. La segunda noción reconoce la adopción de cultivos a nivel local en un momento relativamente tardío, y que dicha innovación fue acompañada por una serie de cambios interrelacionados, por ejemplo la incorporación de nuevas tecnologías. Pero al mismo tiempo, quita centralidad a estas transformaciones y sus presuntas consecuencias, al reconocer el carácter limitado de la producción agrícola y su rol complementario de una economía mixta basada en la profundización de la estrategia cazadora-recolectora. Esto lleva a una revalorización de las continuidades con el pasado, a través del reconocimiento de formas estructurales, largamente reproducidas del modo de vida serrano, que se mostraron relativamente imperturbables más allá de los cambios crecientes del Holoceno Tardío.

\section{Etapas iniciales del proceso}

Los principales interrogantes acerca del proceso de dispersión agrícola en la región han hecho referencia a su origen local o externo, a la forma concreta que adoptaron los sistemas productivos, así como a las etapas de incorporación y su cronología. Para algunos autores, la «etapa agroalfarera» habría comenzado hacia 1000-900 AP, de acuerdo con los primeros fechados de contextos arqueológicos que incluían una asociación distintiva de objetos y rasgos materiales, presumiblemente vinculados con la práctica de cultivos (Berberián 1984; Marcellino et al. 1967). Esta estimación se mantuvo en aportaciones posteriores, esta vez en relación con vestigios arqueológicos directos de cultivos y evidencias del consumo de vegetales domesticados (Pastor y Berberián 2007). Otros autores sostuvieron la posibilidad de un origen más antiguo, $c a$. $1500 \mathrm{AP}$, sin descartar una etapa aún anterior de «agricultura incipiente» (González y Pérez 1972).

Las propuestas de Laguens et al. (2009) se apoyaron en los resultados de análisis de isótopos estables $\left(\delta^{13} \mathrm{C}\right.$ y $\left.\delta^{15} \mathrm{~N}\right)$ sobre muestras de nueve individuos con un rango cronológico entre 4500 y 350 AP. Según esta información, la incorporación plena de la agricultura del maíz habría sido posterior a $1000 \mathrm{AP}$, con una posible fase de transición entre 1300 y 1000 AP. 
La importancia de los estudios de isótopos estables para la determinación de diversos parámetros paleodietarios ha sido ampliamente reconocida, por ejemplo, en casos de este tipo para estimar la proporción de consumo de vegetales de patrón fotosintético C3 y C4. El supuesto fundamental es que la mayoría de los vegetales alimenticios locales (Prosopis spp., Geoffroea decorticans, determinadas gramíneas), tanto por parte de los humanos como de los animales que formaban parte de su alimentación (Lama guanicoe, Ozotoceros bezoarticus), tuvieron patrones fotosintéticos predominantes C3. En consecuencia, la eventual identificación de un cierto aporte de recursos $\mathrm{C} 4$ podría indicar la incorporación de vegetales como Zea mays a la dieta.

Laguens et al. (2009) utilizan estos datos para tratar problemas como la temporalidad del proceso de adopción de la agricultura, sus posibles fases y patrones espaciales. Estos datos isotópicos son valiosos por tratarse del primer conjunto disponible para la región pero, a pesar de ello, desde un punto de vista cuantitativo ( $\mathrm{n}=9$ individuos), resultan desequilibrados en relación con los interrogantes planteados. Por ejemplo, un individuo del sitio Guasmara (valle de Traslasierra) arrojó un fechado de $920 \pm 20$ AP y un valor de $\delta^{13} \mathrm{C}$ de $-17.7 \%$, que indica un nulo o muy escaso consumo de maíz. Desde una perspectiva diacrónica, este individuo fue vinculado con otro procedente de La Granja (Sierras Chicas) y fechado en $1280 \pm 20$ AP, con un consumo asimismo limitado de recursos C4, para sugerir una fase de transición $c a$. 1300-1000 AP previa a la adopción plena de los cultivos. Pero desde una perspectiva espacial, en la comparación entre las diferentes áreas, este mismo individuo de Guasmara se considera representativo del valle de Traslasierra, que pasa a ser definido como un espacio con un desarrollo menor o ralentizado de la agricultura.

Sin embargo, si estos datos son analizados en relación con otros conjuntos macrorregionales más numerosos ( $c a .100$ individuos), por ejemplo aquellos procedentes del Centro-Oeste Argentino (Gil et al. 2010) o Chile Central (Falabella et al. 2007), se tiende a definir un panorama semejante de heterogeneidad, con acentuadas variaciones entre individuos, una tendencia a una mayor incorporación de recursos C4 durante el Holoceno Tardío, pero en forma paulatina. Los resultados contravienen la idea más extendida de una incorporación progresiva, relativamente rápida y de acuerdo con un vector norte-sur, de una agricultura basada en el cultivo del maíz. Por el contrario, se verifica que la importancia dietaria de esta especie fue limitada y su adopción lenta. Dicho proceso pudo comenzar tempranamente, $c a$. 4000-3000 AP, pero sólo en forma tardía, con posterioridad a 1000 AP, se llegó a consolidar una tendencia irreversible hacia una mayor implementación de la estrategia agrícola y un mayor consumo de este recurso en particular (Gil et al. 2010). Los datos de las Sierras Centrales de Argentina parecen congruentes con este contexto macrorregional surandino, entre $30^{\circ}$ y $35^{\circ} \mathrm{S}$, más allá de la necesidad de profundizar sobre esta línea, de incrementar las muestras y alcanzar un mayor conocimiento de la ecología isotópica local (por ejemplo, para calibrar la incidencia de otros posibles recursos $\mathrm{C} 4$ ).

A partir de este panorama y de las expectativas derivadas de otras líneas de información arqueológica, sobre las que incidiremos, se patentiza la necesidad de flexibilizar los modelos de aproximación al problema. La arqueobotánica ha podido confirmar, por ejemplo, la presencia de maíz en contextos tempranos, donde no se verifican las transformaciones materiales y tecnológicas comúnmente asociadas a la práctica 
de cultivos (v.g. alfarería, azadas). Probablemente este maíz era un bien exótico que pudo ser obtenido durante siglos por los cazadores-recolectores a través de intercambios con vecinos agricultores y sin implementar prácticas efectivas de cultivo, lo cual contradice la idea de una incorporación rápida de la agricultura.

El sitio Quebrada del Real 1 comprende una cueva localizada en la Pampa de Achala, en un paisaje de pastizales de altura en las cumbres de las Sierras Grandes (ca. $1900 \mathrm{msnm}$ ), con buen acceso a recursos de caza pero con escasas condiciones para la práctica de cultivos (Rivero et al. 2008-09). El sitio presenta una prolongada secuencia de ocupación que comienza hacia 7400 AP y se extiende hasta el Holoceno Tardío final (ca. 1000-500 AP). El componente 2, datado en $2950 \pm 90$ AP, presenta similitudes con otros contextos contemporáneos de la misma microrregión. Éstas consisten, por ejemplo, en las características de la tecnología que incluyó el uso de puntas de proyectil triangulares con un diseño distintivo, así como la completa ausencia de cerámica (Rivero 2009). Durante esta época la cueva fue utilizada en forma repetida para una intensa actividad de procesamiento y consumo alimenticio, en base a los artiodáctilos gregarios locales (Lama guanicoe, Ozotoceros bezoarticus) y la fauna menor, en particular roedores (Microcavia australis, Galea musteloides, Ctenomys sp.) (Medina et al. 2012). La alta densidad de restos sugiere un uso repetido por parte de grupos relativamente numerosos, en el marco de una intensificación de la estrategia cazadora-recolectora. En la entrada de la cueva se localizan 17 morteros fijos, probablemente empleados para el procesamiento de alimentos de origen vegetal.

La información sobre el uso de recursos vegetales se complementa con siete manos de molino recuperadas en estratigrafía. Se trata de piezas elaboradas en rocas graníticas, con una presencia característica de pequeñas oquedades en la matriz rocosa donde se alojaron microvestigios botánicos (silico-fitolitos, calci-fitolitos y granos de almidón) que fueron analizados. Se identificaron silico-fitolitos pertenecientes a la parte comestible de la planta de maíz (Zea mays) y calci-fitolitos asignados a chañar (Geoffroea decorticans), un fruto de maduración estival en el monte chaqueño que cubre el sur del valle de Traslasierra, entre 10 y $25 \mathrm{~km}$ del sitio. También se registraron granos de almidón de Chenopodium sp. A diferencia de la fauna, del chañar y las Chenopodium, el maíz no pudo ser recolectado en el paisaje local ni en áreas adyacentes. Tampoco existen indicios de su cultivo a nivel local en este momento temprano. Por el contrario, el maíz pudo ser un bien exótico, obtenido a través de la integración de los cazadores-recolectores en redes de interacción de las que también participaban sociedades agricultoras ya asentadas en regiones vecinas como el Noroeste Argentino. El desarrollo de estas redes fue un proceso distintivo durante este período, como se ha observado en este y otros contextos a través de la presencia de bienes exóticos como rocas silíceas y valvas de caracoles (González 1960; Menghin y González 1954). Una de estas valvas, recuperada en este mismo componente de Quebrada del Real 1, fue modificada para la confección de un adorno colgante (Rivero et al. 2008-09).

El segundo contexto con evidencias arquebotánicas tempranas de maíz proviene del sitio Cruz Chiquita 3, un asentamiento a cielo abierto localizado en un entorno ambiental diferente, en el fondo del Valle de Traslasierra ( $c a .900 \mathrm{msnm}$ ) (Pastor 2008). El monte chaqueño circundante ofreció oportunidades para la recolección de 
frutos alimenticios (Prosopis spp., Geoffroea decorticans, Lithraea molleoides, Celtis tala, Condalia spp.) y quizás por ello, así como por el abundante acceso hídrico junto al colector principal (río Jaime), el lugar fue ocupado repetidamente como campamento residencial a lo largo del Holoceno. En este caso, la presencia de maíz en un contexto funerario confirma y amplía la evidencia sobre el acceso temprano a este recurso en la región central de Argentina.

Las excavaciones permitieron registrar una tumba simple en una fosa sin delimitaciones laterales y con una tapa de piedras. En su interior se encontraron los restos de un individuo masculino adulto en posición flexionada, sin objetos de ajuar ni ningún otro acompañamiento. Una datación por AMS sobre una muestra de colágeno óseo sitúa a este contexto en $2466 \pm 51$ AP. En este caso se analizaron los microvestigios botánicos presentes en el tártaro dental, entre los que se identificaron silico-fitolitos pertenecientes al marlo y fruto del maíz. Los datos isotópicos $\left(\delta^{13} \mathrm{C}=-16.1 \%\right.$ ) indican para este individuo una dieta de tipo mixto, que pudo incluir el consumo de vegetales $\mathrm{C} 4$ pero en baja proporción.

\section{La adopción de los cultivos}

Como hemos apuntado, los contextos arqueológicos del período 1000-300 AP comprenden una asociación distintiva de objetos y rasgos materiales que dan cuenta de innovaciones tecnológicas, en alguna medida relacionadas con cambios económicos que incluyeron la práctica de cultivos. Desde $c a$. 2000-1500 AP, por ejemplo, se verifican cambios en el diseño de las puntas de proyectil, con una disminución de su tamaño y peso que ha sido vinculada con la introducción del arco (Pastor et al. 2005). Sin embargo, en el período posterior a $c a$. 1000 AP se incorporaron nuevos materiales y diseños, por ejemplo, puntas talladas en rocas silíceas, triangulares, pequeñas con pedúnculo y aletas, junto con puntas óseas de mayor tamaño y asimismo provistas de un pedúnculo para su fijación en el astil o intermediario. Estos cambios estarían relacionados con una intensificación de la estrategia cazadora, identificable por diversas líneas de información arqueológica, así como un incremento de la conflictividad social con manifestaciones de violencia interpersonal, a través de esqueletos con puntas óseas incrustadas (González 1943; Pastor et al. 2012).

En cuanto a las herramientas para el cultivo, no aparecen palas líticas como las del Noroeste Argentino. Sin embargo, son relativamente comunes los instrumentos conocidos como «hachas» o «azuelas» (Berberián 1984; Serrano 1945), que pudieron ser empleados en tareas agrícolas como el desmonte o para la roturación de los terrenos. Se trata de piezas cilíndricas confeccionadas en rocas duras, con un lado afilado y el otro provisto de un surco profundo para su enmangue. Su costosa elaboración se tradujo en un uso prolongado, con acciones de re-afilado y una baja frecuencia de reemplazo.

En algunos contextos del sur de las Sierras de Córdoba, datados entre 2000 y 1500 AP, aparecen también escasos fragmentos de recipientes cerámicos (Austral y Rocchietti 1995). La frecuencia de estos materiales se incrementa en contextos más recientes, como en los sitios Río Yuspe 11 (pampa de Achala) y Yaco Pampa 1 (valle 
de Guasapampa), datados entre 1500 y 1200 AP (Pastor 2007; Recalde 2014). Sin embargo, la mayor generalización en el uso de esta tecnología es posterior a 1000 $\mathrm{AP}$, cuando se diversificaron las formas y tamaños de los recipientes, las técnicas de decoración e incluso se elaboraron otros tipos de artefactos como figurillas, torteros, cucharas y silbatos (Berberián 1984; Serrano 1945).

Probablemente, la adopción generalizada de la alfarería estuvo asociada a las necesidades de almacenamiento pero, sobre todo, de procesamiento a través del hervido de vegetales domesticados como el maíz y el poroto que empezaban a gravitar en la dieta. De este modo, el ritmo de dispersión de la alfarería y de los cultivos pudo estar estrechamente conectado en este caso particular.

Este panorama resulta consistente con la información isotópica y asimismo con la arqueobotánica. En los depósitos excavados en asentamientos residenciales de este período se identifican restos de vegetales domesticados. En el sitio C.Pun.39 (valle de Punilla) se recuperaron macro y microvestigios (granos de almidón, silico-fitolitos) de maíz, de dos especies domesticadas de poroto (Phaseolus vulgaris y P. lunatus), zapallo y/o cayote (Cucurbita sp.) y Chenopodium sp. (probablemente quínoa). Estos restos aparecieron en contextos de descarte así como en las paredes internas de fragmentos cerámicos o sobre las superficies activas de útiles de molienda (Medina et al. 2009). En el sitio Puesto La Esquina 1 (pampa de Olaen). se registraron restos de maíz y las mismas dos especies domesticadas de poroto, en contextos de descarte o en las paredes internas de fragmentos cerámicos (Medina y López 2005-06). Por su parte en Arroyo Tala Cañada 1 (valle de Traslasierra) se identificaron restos de maíz, zapallo y las dos especies de poroto en contextos de descarte (Pastor 2007-08).

Durante los años de la conquista (siglo XVI) los españoles produjeron una serie de documentos escritos que se han conservado y permiten una aproximación a las características de los sistemas productivos de ese período y su variabilidad. Como hemos apuntado, son frecuentes las referencias a las «chacaras» y «sementeras» donde los indígenas cultivaban maíz, «frijoles» (Phaseolus spp.), zapallo, quinoa, «maní» (Arachis hypogaea) y «camote» (Ipomoea batatas). Algunas de estas especies han sido registradas en los contextos arqueológicos y posiblemente otras lo sean en el futuro, con la profundización de los estudios arqueobotánicos. Estos datos sugieren la existencia de policultivos y que más allá de la importancia relativa de cada especie o variedad, así como las posibles variaciones espacio-temporales, se habría desarrollado una estrategia tendiente a la diversificación, a través de una lógica de tipo campesino que apuntaba menos a la maximización de beneficios que a asegurar un cierto nivel de producción.

Aunque existen algunas menciones puntuales sobre el uso de regadíos (acequias), la forma productiva predominante sería de secano. Esta forma basada en el aporte del agua de lluvia implicó una escasa inversión tecnológica y una cierta cuota de movilidad, por la necesidad de barbechos prolongados para la recuperación de la fertilidad del suelo, en un contexto de cierta disponibilidad de terrenos por parte de numerosos grupos locales. Este tipo de producción explicaría la ausencia de una infraestructura productiva que pueda ser reconocida a través de vestigios arquitectónicos, como muros de contención, canales o represas. El trabajo simultáneo sobre varias parcelas de secano, distribuidas en diferentes paisajes serranos con variadas condiciones para la 
agricultura, tanto como el policultivo, habrían formado parte de estrategias de diversificación productiva, por medio del aprovechamiento de la variabilidad microambiental (tipos de suelos, climas) y limitando el efecto perjudicial de factores y agentes de acción localizada (granizo, plagas, desigual distribución de las precipitaciones) (Medina y Pastor 2006).

Este tipo de agricultura se define como una producción a pequeña escala, complementaria de una economía desarrollada en torno a la intensificación de tendencias iniciadas en períodos anteriores, a través de una mayor explotación de los recursos silvestres y la ocupación efectiva de paisajes marginales (Pastor et al. 2012). Las menciones sobre regadíos parecen representar situaciones muy puntuales, con una mayor tecnificación orientada hacia una profundización del cambio económico, con un incremento de la producción que pudo acarrear consecuencias sociales y políticas poco conocidas. En el propio título de la encomienda que se auto-asignó Jerónimo Luis de Cabrera, gobernador del Tucumán y fundador de Córdoba, en la zona de Quilino (Sierras del Norte), se menciona, entre otros, a un conjunto de cinco pueblos: Quilinon (cacique Anime), Sanchinta (caciques Osile y Nico), Ibra Sacat (cacique Ibra), Catlan Sacat (cacique Tacto) y Pitanga (cacique Conys). Estos pueblos con sus caciques fueron considerados una «parcialidad» que estaba poblada junto a una acequia llamada Ybram Mampa (Montes 2008), lo cual sugiere un cierto nivel de pertenencia y coordinación política, posiblemente en torno a la gestión colectiva de esa infraestructura de riego.

Otras fuentes advierten sobre la variabilidad local de los sistemas productivos, en parte determinada por diferencias microambientales. Así tenemos el caso de los sembrados en tierras inundables, que difieren de los cultivos de secano o por riego artificial. De un modo general son mencionados por el jesuita Alonso de Barzana en su conocida carta de 1594, al referirse a la forma de sustento de los indígenas del Tucumán:

«El modo de vivir de todas estas naciones es el ser labradores. Sus ordinarias comidas son maíz, lo cual siembran en mucha abundancia; también se sustentan de grandísima suma de algarroba, la cual cogen por los campos todos los años al tiempo que madura y hacen della grandes depósitos; y cuando no llueve para coger maíz ó el río no sale de madre para poder regar la tierra, pasan sus necesidades con esta algarroba...» (Berberián 1987: 254; la cursiva es nuestra).

Este sistema habría sido aplicado por los indígenas del pueblo de Tulián, quienes habitaban en la cuenca baja del río Pichanas, en la planicie al sur de las Salinas Grandes. En períodos de crecientes este curso se derramaba por la planicie hasta alcanzar la depresión de las salinas. Según testimonios judiciales, Tulián era el último pueblo y sus indios sembraban «sus chacaras en el arena donde se consume dicho río» (Montes 2008: 370).

El calendario de investigación futuro debe apuntar a identificar y describir esta variabilidad. La información disponible es aún escasa y fragmentaria, pero no obstante permite vislumbrar diversos paisajes productivos. La información polínica del sitio C.Pun.39 (valle de Punilla) indica que en los alrededores de los espacios habitacionales crecían con abundancia las quenopodáceas-amarantáceas (Medina et al. 2008). Este patrón admite dos interpretaciones no excluyentes, de hecho, ambos escenarios son considerados como plausibles. Por un lado, podría revelar la presencia de cultivos 
andinos como la quínoa (Chenopodium quinoa). Hemos visto que este tipo de plantas fueron consumidas en el sitio, tal como indican los granos de almidón adheridos a las paredes internas de fragmentos cerámicos. La segunda interpretación se relaciona con las evidencias de períodos alternativos de ocupación y abandono del lugar, $c a$. 850-500 AP (Pastor et al. 2013). En esta época el sitio habría constituido un hábitat perturbado por una actividad antrópica recurrente, con fines residenciales y agrícolas, lo cual pudo acelerar el avance, especialmente en fases de desocupación, de plantas de este tipo que encuentran condiciones favorables en esta clase de terrenos.

Estos datos devuelven la imagen de C.Pun.39 como un paisaje relativamente abierto en el monte chaqueño, con algunas viviendas agrupadas y posiblemente cultivos de quínoa creciendo en los alrededores. Estas viviendas, de tipo casa-pozo (Berberián 1984), estaban construidas con materiales livianos y no eran ocupadas de forma permanente aunque sí reutilizadas tras períodos variables de desocupación. Durante estos últimos, avanzarían las plantas herbáceas incluyendo Chenopodium silvestre así como leñosas de porte arbustivo como Acacia caven y Condalia spp.

La información de Arroyo Tala Cañada 1 (valle de Traslasierra) ayuda a comprender las características del espacio productivo, al nivel de los pequeños huertos ubicados entre las viviendas (Pastor y López 2010). La excavación sobre dos sectores contiguos, distanciados apenas ocho metros, permitió reconocer vestigios de una estructura habitacional y de un espacio destinado al cultivo. En el primer caso, se identificó un piso de sedimento consolidado al que se asociaban dos agujeros de poste y diversos restos en posición primaria, entre ellos fragmentos de dos recipientes cerámicos que habrían colapsado in situ. A partir de una muestra de carbón se obtuvo un fechado para este contexto de $900 \pm 70 \mathrm{AP}$.

En el segundo sector, sobre una superficie excavada de $3 \times 2 \mathrm{~m}$, se identificaron surcos paralelos de unos $30 \mathrm{~cm}$ de ancho que aparentemente se extendían más allá del área intervenida. En todo el sedimento se encontraron abundantes residuos domésticos, entre ellos cotiledones carbonizados de poroto común cultivado (Phaseolus vulgaris var. vulgaris), uno de los cuales fue datado por AMS en $1028 \pm 40$ AP. Esta fecha indica una cierta concomitancia con la ocupación de la vivienda cercana, aproximadamente entre los siglos X y XIII de nuestra era.

El análisis de los micro-vestigios vegetales asociados a los surcos arrojó resultados significativos en relación al tipo de agricultura practicada en el lugar. En primer término, se identificaron silico-fitolitos atribuidos específicamente a las hojas de maíz y poroto, es decir a las partes no comestibles de las plantas, lo cual confirma el cultivo in situ de ambas especies. Por otra parte, la observación de las uniones celulares (espodogramas) de las gramíneas silvestres que crecieron conjuntamente, con predominio de las uniones de dos y tres células, indica que estos vegetales se desarrollaron con el único aporte del agua de lluvias. Estudios experimentales señalan la ocurrencia de un mayor número de uniones en el caso de las parcelas regadas artificialmente, entre 10 hasta más de 100 células unidas, debido a un mayor aporte de sílice al sustrato (Rosen y Weiner 1994). El corto número de uniones en esta parcela arqueológica es consistente con cultivos de secano.

El cultivo combinado de maíz y poroto en una misma parcela es una práctica frecuente en numerosos sistemas productivos basados en técnicas tradicionales, dado 
que ambas especies se complementan beneficiosamente. El poroto favorece el crecimiento del maíz al tomar nitrógeno de la atmósfera y fijarlo como nutriente en el suelo, mientras que las cañas de maíz le sirven de apoyo, puesto que el poroto es una planta de tipo trepador. Los cultivos llevados a cabo en este sitio consistieron en huertos pequeños próximos a las viviendas, donde podían obtenerse diversos productos entre los que se destaca el maíz. La función de los surcos habría sido limitar la erosión y facilitar la retención del agua precipitada. Esta forma de producción habría estado generalizada en la época y de este modo se habría definido, en sus rasgos fundamentales, el aspecto que llegó a alcanzar el paisaje agrícola en las sierras. Es por ello que en el siglo XVI el cronista Diego Fernández, en el momento de describir el carácter semi-subterráneo de las habitaciones construidas por los indígenas, señaló que los poblados no parecían tales a la distancia, «a no ser por los maizales» que los sobrepasaban en altura (Berberián 1987: 53).

\section{Producción agrícola, procesos económicos y cambio social}

Los documentos del siglo XVI dan cuenta de una producción agrícola indígena de cierto volumen, pero también advierten sobre el carácter inseguro de dicho aporte. En su informe de servicios, el capitán Hernán Mejía Mirabal declaró haber obtenido sustento para el asiento español en sus primeros años, saliendo en muchas ocasiones por orden del gobernador con gente de guerra y retornando al fuerte con «tres mil fanegas de maíz, frijoles y zapallos» (Piana de Cuestas 1992: 72). Sin embargo, eran comunes las crisis agrícolas desencadenadas por factores diversos actuando aislados o en combinación, como las sequías, tormentas de granizo, plagas de langostas, gusanos o, como acabamos de ver, conflictos y saqueos tanto a nivel intra como interétnico. Estas crisis eran capaces de afectar a grupos locales particulares o bien a comarcas y valles enteros. En tales casos era fundamental el acceso a los recursos silvestres. Como señalaba el Padre Barzana en su carta referida supra, si las lluvias eran insuficientes y no permitían recoger maíz, o si los ríos no salían de su cauce para fertilizar la tierra, entonces los indígenas pasaban sus necesidades con la algarroba (Prosopis spp.) que recogían en grandes cantidades y de la que hacían importantes depósitos (Berberián 1987: 254).

Los patrones isotópicos parecen avalar la idea de un mayor consumo de maíz con posterioridad a $c a$. $1000 \mathrm{AP}$, pero también destacan la variabilidad inter-individuos que entendemos consistente con una fase de transición agrícola, con un aporte relativamente limitado de este recurso y una dieta de tipo mixto. Los procesos económicos de este período se definen, de hecho, por las estrategias orientadas a sostener un modo de vida tradicional cazador-recolector, en un contexto de crecimiento demográfico y restricciones territoriales. En este marco el cultivo de diferentes especies permitió incrementar la productividad y brindar un aporte complementario, consistentemente con una lógica de diversificación de las actividades y recursos aprovechados.

La información da cuenta de una mayor explotación de los recursos silvestres. Los conjuntos arqueofaunísticos provenientes de contextos residenciales indican la captura de una amplia gama de especies, principalmente artiodáctilos gregarios como 
guanacos (Lama guanicoe) y venados de las pampas (Ozotoceros bezoarticus), pero también animales de hábitos solitarios y/o menor porte como las corzuelas (Mazama guazoupira), armadillos (Chaetophractus sp., Dasypus sp.), roedores (Galea sp., Microcavia sp., Ctenomys sp.), lagartos (Tupinambis sp.) y aves (Nothura sp., Eudromia sp.). Las innovaciones tecnológicas como el arco y la cerámica, introducidas en un período anterior pero generalizadas en éste, dan cuenta de diseños especializados para la cacería de presas diversas, así como nuevas formas de procesar los alimentos, como el hervido en ollas, que en parte se refleja en el intenso trozamiento de las carcasas (Medina y Pastor 2012; Pastor et al. 2005). Los datos arqueobotánicos indican la recolección de diversos vegetales (Prosopis sp., Geoffroea decorticans, Zizyphus mistol, Phaseolus silvestres, posiblemente algunas gramíneas), en tanto que los fragmentos de cáscaras muestran el acceso regular a los huevos de dos especies de ñandú (Rhea americana y R. pennata) (Medina et al. 2009; Medina et al. 2011).

Un proceso notable, cuyos antecedentes se remontan hasta $c a$. $1400 \mathrm{AP}$, fue la ocupación efectiva de microambientes marginales como las sierras noroccidentales de Córdoba (Guasapampa, Pocho, Serrezuela), en el límite con las Salinas Grandes y los Llanos de La Rioja. Se trata de entornos dotados de los típicos recursos silvestres del monte chaqueño, pero con agua escasa o muy escasa en algunas áreas. La ocupación más intensa aunque estacional de estos paisajes, hasta entonces poco tenidos en cuenta, apuntó en el sentido de la reproducción de una lógica cazadora-recolectora en un contexto de expansión demográfica y territorial (Pastor 2012; Recalde 2014).

Las consecuencias acumulativas e interconectadas de estas innovaciones desencadenaron cambios en las estructuras sociales y políticas, a pesar de que las estrategias se orientaran hacia la conservación de los antiguos modos de vida. Las demandas asociadas al cuidado de los cultivos implicaban la protección de las parcelas durante el crecimiento de las plantas, así como de las cosechas y reservas almacenadas, más allá de que la organización de estas prácticas permitiera el sostenimiento de una forma de vida móvil o semi-sedentaria (Medina et al. 2014; Pastor et al. 2013). Esto llevó a la instauración de una territorialidad de tipo restrictivo, aplicada a terrenos con potencial agrícola así como a espacios destinados a la caza y recolección («algarrobales», «cazaderos»), revirtiendo en un incremento de la conflictividad social (Pastor 2012; Pastor et al. 2012).

Las condiciones de reproducción social se afianzaron progresivamente en el aporte de los cultivos y en un acceso fluido a espacios variados de explotación de recursos silvestres. Este contexto particular habría favorecido la definición de los grupos locales como unidades sociales relativamente «cerradas», con relaciones de reciprocidad interna positiva y externa negativa. Las numerosísimas unidades políticas mencionadas en las fuentes del siglo XVI no eran más que pequeñas comunidades cuyos integrantes estaban unidos por lazos de parentesco, en una estructura de linajes familiares interrelacionados. Esta modalidad supone la transformación de una forma de organización previa, extendida entre los cazadores-recolectores, en base a grupos locales «abiertos» con una reciprocidad externa positiva.

La integración de estas formaciones políticas comunitarias supuso un juego de acuerdos y tensiones: la negociación en un frente interno para contravenir tendencias autonómicas de unidades domésticas y linajes familiares, así como en un frente ex- 
terno con otras formaciones locales o extrarregionales, implicando alternativas variables y cambiantes entre la alianza y el conflicto abierto. Entre las prácticas orientadas a desarrollar las redes de alianza, a contener o afrontar la conflictividad social, las fuentes escritas del tiempo de la conquista destacan los intercambios matrimoniales y la celebración de rituales colectivos («juntas y borracheras») (Montes 2008; Piana de Cuestas 1992). Las fuentes relacionan a estos rituales con el consumo de alimentos y bebidas, llevado a cabo en coincidencia con actividades extractivas como las cacerías y en particular la recolección de la algarroba. La arqueología del período posterior a ca. 1000 AP (con algunos antecedentes más tempranos) muestra el desarrollo de un ámbito de participación colectiva, separado de los espacios residenciales, en sitios de propósitos especiales donde se conservaron, entre otros materiales, vestigios de la preparación y consumo de grandes volúmenes de alimentos (Pastor 2007). La consolidación de esta esfera de participación comunitaria, en forma concomitante con la introducción de los cultivos, manifiesta la irreversible transformación de los antiguos modos de vida, a través del afianzamiento de las formaciones políticas suprafamiliares, en tanto estructuras segmentarias con una cierta cohesión y jerarquización interna. Lo que nos interesa destacar es que los paisajes, prácticas y sentidos en torno a los cuales se desarrollaron estas celebraciones estaban vinculados con la caza y recolección, y no así con los cultivos, lo cual advierte sobre la importancia económica de los recursos silvestres y sobre las estrategias orientadas hacia la conservación del modo de vida tradicional, irreversiblemente modificado por la agudización de sus contradicciones.

\section{Consideraciones finales}

En el caso de la región y período que nos ocupa, las transformaciones ligadas a la introducción de vegetales domesticados a la dieta y prácticas de cultivo se relacionaron tradicionalmente con un concepto de «revolución», en el sentido de un cambio histórico con consecuencias profundas y de largo plazo. A pesar de ello, hemos sugerido que la manipulación, consumo e incluso el cultivo de estos vegetales no condujeron en forma directa a cambios radicales. Las transformaciones fueron graduales, paulatinas, sin provocar modificaciones estructurales inmediatas.

Lo que se observa es que las innovaciones no se impusieron en forma rápida y asociada, como un «paquete neolítico»o «formativo», incluso relacionado con un posible reemplazo poblacional (la «inmigración de pueblos agricultores»). Por el contrario, son notorias las continuidades con el pasado y la orientación de las estrategias económicas y sociales hacia la conservación de los modos de vida tradicionales. A lo largo de siglos, vegetales como el maíz o tecnologías como la cerámica, sólo fueron adoptados en cuotas muy limitadas y probablemente en contextos particulares, distintos de los más cotidianos (v.g. rituales). Aunque no contamos con información precisa, otro tanto podría suponerse con respecto a la incorporación de otras plantas como Phaseolus spp. o Chenopodium quinoa. Por su parte, la forma predominante de agricultura de secano no llegó a requerir un sedentarismo pleno, lo cual permitió la vigencia (así como la ampliación) de los circuitos de movilidad propios de los 
cazadores-recolectores. Esto no quita que, a largo plazo, llegaran a producirse transformaciones profundas, como también hemos apuntado.

Aunque estas ideas aparecen como contrapuestas a los modelos sobre la dispersión agrícola en las Sierras Centrales de Argentina, se aproximan por otro lado a los escenarios reconocidos en regiones conectadas del sur andino, como Cuyo y Chile Central (Falabella et al. 2007; García 2010; Gil et al. 2010). En todos estos casos se ha observado la manipulación temprana de vegetales domesticados como el maíz o la quínoa por parte de cazadores-recolectores que no cultivaban ni producían cerámica, una adopción no inmediata de la agricultura del maíz, la incorporación gradual de otras especies y variedades domesticadas y al mismo tiempo, claras continuidades con el pasado que se expresan en la importancia económica de los recursos silvestres y en formas sostenidas de movilidad residencial. Los procesos centrados en la intensificación de la estrategia agrícola, así como los cambios sociales relacionados, aparecen limitados a áreas puntuales y a momentos muy tardíos de la secuencia prehispánica.

Más allá de este escenario macrorregional, vigente en el sur andino entre los $30^{\circ}$ y $35^{\circ} \mathrm{S}$, algunos de estos elementos aparecen en diversas combinaciones en una variedad de trayectorias globales de transición a la agricultura, sin conexiones directas o indirectas. De este modo, si bien nuestro objetivo de investigación se relaciona con un caso específico en el sur de Sudamérica, las tendencias identificadas se vinculan con una discusión más amplia que indaga acerca de la variabilidad y aspectos singulares, así como los patrones más profundos y compartidos que incidieron en la dirección del cambio histórico.

Tomemos en cuenta por ejemplo, algunos de los ejes del debate en el Viejo Mundo. Tradicionalmente los modelos dominantes de expansión de la agricultura en Europa veían el proceso de «neolitización» como un paquete integrado, que incluía la inmigración desde centros del Cercano Oriente de pueblos que portaban consigo sus culturas, tecnologías, plantas, animales domesticados y formas de organización. Estas transformaciones de tipo «revolucionario», con la imposición de un nuevo «paquete» de rasgos asociado al desplazamiento y reemplazo de poblaciones, parecen haber ocurrido efectivamente en muchas ocasiones (Bogaard et al. 2013; Cramp et al. 2014; Gamba et al. 2011). Pero ésta no sería más que una alternativa en un escenario global diverso. Se tiende a imponer la idea de la neolitización como un proceso «en mosaico», con una marcada variabilidad cultural, un impacto diferencial de los cambios en las distintas regiones, en ocasiones cambios rápidos y «en paquete» y en otros casos lo contrario, permanencias con el pasado e incorporación gradual de los elementos novedosos (Amkreutz et al. 2008; Cubas y Fano 2011; Cramp et al. 2014; Hervella et al. 2012). Se ha definido un «paradigma de continuidad», especialmente en Europa Atlántica, que implica una valorización del Mesolítico, una evaluación detenida de sus formas locales, como instancia previa para comprender la implantación del Neolítico y las transformaciones que pudo acarrear en cada caso, a partir de un rol activo de las poblaciones indígenas (Silva y Frank 2013). Esto incluye la diversidad de vínculos de co-existencia, segregación, intercambio, conflicto, etc., entre grupos cazadores-recolectores y agricultores-ganaderos (Amkreutz et al. 2008; Marchand 2009; Perrin 2003). 
De este modo se ha desestimado la inmediatez o la existencia de relaciones estructurales entre agricultura (o ganadería) y cambio social (Hernando 1999). Los pueblos europeos occidentales del Neolítico deberían ser considerados a lo sumo como horticultores, con un pequeño porcentaje de la subsistencia cubierto por los productos de la agricultura y el pastoreo, y no como agricultores plenos. Incluso su modo de vida pudo ser más móvil que algunos de sus antepasados, que habían desarrollado formas sedentarias o semi-sedentarias a finales del Mesolítico (Silva y Frank 2013). En este sentido, además de la gradualidad, se ha advertido acerca del carácter reversible y no unidireccional de las trayectorias de adopción de las economías productoras (Layton et al. 1991). Por ejemplo, para las islas británicas, se ha sugerido un retroceso de la agricultura tras una limitada adopción a comienzos del Neolítico hasta su imposición definitiva recién en la Edad del Bronce (Stevens y Fuller 2012).

Como sostuvimos al comienzo, el cuerpo de información con el que contamos para analizar el proceso de dispersión agrícola en las Sierras Centrales de Argentina en el Holoceno Tardío es aún muy fragmentario y requiere el desarrollo de nuevas investigaciones. No obstante, permite trazar un cuadro general así como definir algunas tendencias. Se aprecian claras semejanzas y conexiones con el escenario macrorregional surandino, así como patrones comunes con una extensa serie de casos a nivel global, lo cual permite vincular algunas de las conclusiones con una discusión más amplia que sobrepasa los límites del contexto local. También se vislumbran los ejes que deben regir la agenda futura, abierta a diferentes líneas de indagación. En cuanto a los estudios de isótopos estables, es imprescindible incrementar el tamaño de las muestras e introducirse en el conocimiento de la ecología isotópica regional, como instancia previa para calibrar la estimación del aporte del maíz a la dieta. Los estudios arqueobotánicos, por su parte, deben apuntar a una mayor comprensión de la interacción entre las sociedades humanas y el entorno vegetal, incluyendo especies y variedades tanto silvestres como domesticadas, sus modos de empleo y ritmos de adopción. También será fundamental incorporar nuevos estudios sobre parcelas de cultivo arqueológicas, como aproximación a los antiguos sistemas productivos, a sus formas más extendidas en la región y asimismo a su variabilidad espacio-temporal.

\section{Referencias bibliográficas}

Amkreutz, Luc, Bart Vanmontfort y Leo Verhart

2008 «Diverging Trajectories? Forager-Farmer Interaction in the Southern Part of the Lower Rhine Area and the Applicability of Contact Models», en Creating Communities. New Advances in Central European Neolithic Research, Daniela Hofmann y Penny Bickle, eds., pp. 11-31. Oxford: Oxbow Books.

AustRal, Antonio y Ana María Rocchietti

1995 «Arqueología de la pendiente oriental de la sierra de Comechingones», en Actas y Memorias del XI Congreso Nacional de Arqueología Argentina 10: 61-80. San Rafael, Mendoza; Museo Municipal de Historia Natural.

BERBERIÁN, Eduardo

1984 «Potrero Garay: una entidad sociocultural tardía de la región serrana de la provincia de Córdoba (Rep. Argentina)». Comechingonia 4: 71-138. 
1987 Crónicas del Tucumán. Siglo XVI. Córdoba: Editorial Comechingonia.

1999 «Sierras Centrales», en Nueva Historia de la Nación Argentina, Academia Nacional de la Historia, ed., pp. 135-158. Buenos Aires: Editorial Planeta.

Bogaard, Amy, Rebecca Fraser, Tim Heaton, Michael Wallace, Petra Vaiglova, Charles Michael, Jones Glynis, Richard Evershed, Amy Styring, Niels Andersen, Rose-Marie Arbogast, László Bartosiewicz, Armelle Gardeisen, Marie Kanstrup, Ursula Maier, Elena Marinova, Lazar Ninov, Marguerita SchÄEfer y Elisabeth StePhan

2013 «Crop Manuring and Intensive Land Management by Europe's First Farmers». Proceedings of the National Academy of Sciences 110 (31): 12589-12594.

Cramp, Lucy, Jennifer Jonnes, Alisom Sheridan, Jessica Smyth, Helen Whelton, Jacqui Mulville, Niall Sharples y Richard Evershed

2014 «Immediate Replacement of Fishing with Dairying by the Earliest Farmers of the Northeast Atlantic Archipelagos». Proceedings of the Royal Society B 281: 20132372. http://dx.doi.org/10.1098/rspb.2013.2372.

Cubas, Miriam y Miguel Fano

2011 «Los primeros campesinos del Cantábrico: una revisión de la información disponible y de los modelos propuestos». Férvedes 7: 77-86.

Falabella, Fernanda, M. Teresa Planella, Eugenio Aspillaga, Lorena Sanhueza y Robert ТYКОT

2007 «Dieta en sociedades alfareras de Chile Central: aportes de análisis de isótopos estables». Chungara 39 (1): 5-27.

Gamba, Cristina, Eva Fernández, Miriam Tirado, Marie France Deguilloux, Marie-Hélène Pemonge, Pilar Utrilla, Manuel Edo, Miquel Molist, Rita Rasteiro, Lounès Chikhi y Eduardo ArRoyo-PARDo

2011 «Ancient DNA from an Early Neolithic Iberian Population Supports a Pioneer Colonization by First Farmers». Molecular Ecology 21 (1): 45-56.

GARCíA, Alejandro

2010 Arqueología prehistórica de San Juan. San Juan: Editorial Fundación Universidad Nacional de San Juan.

GiL, Adolfo, Gustavo Neme y Robert Tүкот

2010 «Isótopos estables y consumo de maíz en el centro-oeste argentino: tendencias temporales y espaciales». Chungara 42 (2): 497-513.

GonZÁLEZ, Alberto Rex

1943 «Arqueología del yacimiento indígena de Villa Rumipal (Provincia de Córdoba)». Publicaciones del Instituto de Arqueología, Lingüistica y Folklore (U.N.Cba.) IV.

1960 «La estratigrafía de la gruta de Intihuasi (Prov. de San Luis, R.A.) y sus relaciones con otros sitios precerámicos de Sudamérica». Revista del Instituto de Antropología 1: 5-296.

GonzÁlez, Alberto Rex y José Pérez

1972 Argentina indígena. Visperas de la Conquista. Buenos Aires: Paidós.

HeRnANDO, Almudena

1999 Los primeros agricultores de la Península Ibérica. Madrid: Editorial Síntesis. 
Hervella, Montserrat, Neskuts Izaguirre, Santos Alonso, Rosa Fregel, Antonio Alonso, Vicente CABrera y Concepción De La Rúa

2012 «Ancient DNA from Hunter-Gatherer and Farmer Groups from Northern Spain Supports a Random Dispersion Model for the Neolithic Expansion into Europe». Plos One 7 (4): 1-10.

LAGUENS, Andrés

1999 Arqueología del contacto hispano-indígena. Un estudio de cambios y continuidades en las Sierras Centrales de Argentina. BAR International Series 801. Oxford: Archaeopress.

Laguens, Andrés y Mirta Bonnín

2009 Sociedades indígenas de las Sierras Centrales. Arqueología de Córdoba y San Luis. Córdoba: Editorial de la Universidad Nacional de Córdoba.

Laguens, Andrés, Mariana Fabra, Guaciara Santos y Darío Demarchi

2009 «Palaeodietary Inferences Based on Isotopic Data for Pre-Hispanic Populations of the Central Mountains of Argentina». International Journal of Osteoarchaeology 19: 237-249.

LAYTON, Robert, Robert Foley y Elizabeth WiLLIAMS

1991 «The Transitions between Hunting and Gathering and the Specialized Husbandry of Resources: A Socio-Ecological Approach». Current Anthropology 32 (3): 255274.

Marcellino, Alberto, Eduardo Berberián y José Pérez

1967 «El yacimiento arqueológico de Los Molinos (Dpto. Calamuchita, Córdoba)». Publicaciones del Instituto de Antropología XXVI.

MARCHAND, Grégor

2009 «Relations entre chasseurs-cueilleurs et agriculteurs en Europe occidentale: les echánges comme condition de la néolithisation?», en La Révolution néolithique dans le monde, Jean-Paul Demoule, ed., pp. 283-300. Paris: CNRS Editions.

MEDINA, Matías y Laura LóPEz

2005-06 «Evidencias prehispánicas de Phaseolus spp. en Puesto La Esquina 1 (Córdoba, Argentina)». Arqueología 13: 241-245.

Medina, Matías y Sebastián PAstor

2006 «Chacras dispersas. Una aproximación etnográfica y arqueológica al estudio de la agricultura prehispánica en la región serrana de Córdoba (Argentina)». Comechingonia 9: 103-121.

2012 «Zooarqueología de sitios residenciales tardíos de las Sierras de Córdoba (Argentina, ca. 1100-300 AP): avances y perspectivas», en Temas de Arqueología: Estudios Tafonómicos y Zooarqueológicos, Alejandro Acosta, Daniel Loponte y Leonardo Mucciolo, eds., II, pp. 45-66. Buenos Aires: Asociación Amigos del Instituto Nacional de Antropología y Pensamiento Latinoamericano.

Medina, Matías, Silvia GriLl y Laura LóPez

2008 «Palinología arqueológica: su implicancia en el estudio del prehispánico tardío de las Sierras de Córdoba (Argentina)». Intersecciones en Antropología 9: 99-112.

MEdinA, Matías, Laura LóPEZ y Eduardo BERBERIÁn

2009 «Agricultura y recolección en el Tardío Prehispánico de las Sierras de Córdoba (Argentina): el registro arqueobotánico de C.Pun.39». Arqueología 15: 217-230. 
Medina, Matías, Sebastián Pastor, Eduardo Apolinaire y Lucas Turnes

2011 «Late Holocene Subsistence and Social Integration in Sierras of Córdoba (Argentina): the South-American Ostrich Eggshells Evidence». Journal of Archaeological Science 38: 2071-2078.

Medina, Matías, Pablo Teta, Pablo y Diego Rivero

2012 «Burning Damage and Small-Mammal Human Consumption in Quebrada del Real 1 (Córdoba, Argentina): An Experimental Approach». Journal of Archaeological Science 39: 737-743.

Medina, Matías, Sebastián Pastor y Eduardo Berberián

2014 «'Es gente fazil de moverse de una parte a otra'. Diversidad en las estrategias de subsistencia y movilidad prehispánicas tardías (Sierras de Córdoba, Argentina)». Complutum 25 (1): 73-88.

Menghin, Osvaldo y Alberto Rex GonZÁLez

1954 «Excavaciones arqueológicas en el yacimiento de Ongamira, Córdoba (Rep. Argentina). Nota preliminar». Notas del Museo de La Plata XVII, antropología $\mathrm{n}^{\circ}$ 67: 213-267.

Montes, Aníbal

2008 Indígenas y conquistadores de Córdoba. Buenos Aires: Ediciones Isquitipe.

PASTOR, Sebastián

2007 «'Juntas y cazaderos'. Las actividades grupales y la reproducción de las sociedades prehispánicas de las Sierras Centrales de Argentina», en Procesos Sociales Prehispánicos en el Sur Andino. La Vivienda, la Comunidad y el Territorio, Axel Nielsen, María C. Rivolta, Verónica Seldes, María M. Vázquez y Pablo Mercolli, eds., pp. 361-376. Córdoba: Editorial Brujas.

2007-08 «Arroyo Tala Cañada 1 (valle de Salsacate). Espacio doméstico y productivo en el sector central de las Sierras de Córdoba (Argentina) durante el Período Prehispánico Tardío (ca. 1000-300 AP)». Arqueología 14: 41-75.

2008 «Acerca de una inhumación temprana ( $c a$. 2500 AP) en el sitio Cruz Chiquita 3 (valle de Salsacate, Córdoba, Argentina)». Comechingonia 11: 127-142.

2012 «Arte rupestre, paisaje y tensión social: un caso de estudio en Córdoba, Argentina». Revista Chilena de Antropología 26: 7-32.

PASTOR, Sebastián y Eduardo BERBERIÁN

2007 «Arqueología del sector central de las Sierras de Córdoba (Argentina). Hacia una definición de los procesos sociales del período prehispánico tardío (900-1573 d.C.)». Intersecciones en Antropología 8: 31-47.

PASTOR, Sebastián y Laura LóPEZ

2010 «Consideraciones sobre la agricultura prehispánica en el sector central de las Sierras de Córdoba», en Arqueología de la agricultura: casos de estudio en la Región Andina Argentina, Alejandra Korstanje y Marcos Quesada, eds., pp. 208-233. Tucumán: Editorial Magma.

Pastor, Sebastián, Eduardo Pautassi y Diego Rivero

2005 «Los sistemas de armas de las comunidades agroalfareras de Córdoba: una aproximación arqueológica y experimental», en Actas del XIII Congreso Nacional de Arqueología Argentina 4: 253-266. Córdoba. 
Pastor, Sebastián, Matías Medina, Andrea Recalde, Laura LóPez y Eduardo Berberián

2012 «Arqueología de la región montañosa central de Argentina. Avances en el conocimiento de la historia prehispánica tardía». Relaciones de la Sociedad Argentina de Antropología 37 (1): 89-112.

PAstor, Sebastián, Matías Medina y Eduardo Berberián

2013 «Poblados, casas y maizales. Arqueología del espacio residencial y productivo en las Sierras Centrales de Argentina (ca. 1100-300 AP)». Revista Española de Antropología Americana 43 (1): 31-55.

PERRIN, Thomas

2003 «Mesolithic and Neolithic Cultures Co-existing in the Upper Rhône Valley». Antiquity 77: 732-739.

Piana de Cuestas, Josefina

1992 Los indígenas de Córdoba bajo el régimen colonial (1570-1620). Córdoba: Dirección General de Publicaciones de la Universidad Nacional de Córdoba.

RECALDE, Andrea

2014 «Construcción de paisajes en el oeste de las Sierras de Córdoba durante el prehispánico tardío ( $c a$. 1500-400 AP). Diversidad de prácticas y sentidos en torno al arte rupestre». Arqueología 20 (2): 207-223.

Rivero, Diego

2009 Ecología de cazadores-recolectores del Sector Central de las Sierras de Córdoba (Rep. Argentina). Oxford: BAR International Series 2007.

Rivero, Diego y Eduardo BERBERIÁN

2008 «El poblamiento de la región central del territorio argentino durante la transición Pleistoceno-Holoceno (12000-9000 AP)». Revista Española de Antropología Americana 38 (2): 17-37.

Rivero, Diego, Sebastián Pastor y Matías Medina

2008-09 «Intensificación en las Sierras de Córdoba. El abrigo rocoso Quebrada del Real 1 (ca. 6000-500 AP, Córdoba, Argentina)». Anales de Arqueología y Etnología 6364: 227-246.

Rosen, Arlene y Stephen WeINER

1994 «Identifying Ancient Irrigation: A New Method Using Opaline Phytoliths from Emmer Wheat». Journal of Archaeological Science 21: 125-132.

SERrano, Antonio

1945 Los Comechingones. Serie Aborígenes Argentinos, vol. I. Córdoba: Instituto de Arqueología, Lingüística y Folklore de la Universidad Nacional de Córdoba.

SiLVA, Fabio y Roslyn Frank

2013 «Deconstructing the Neolithic Myth: The Implications of Continuity for European Late Prehistory». Anthropological Notebooks 19 (supplement): 223-235.

Stevens, Chris y Dorian Fuller

2012 «Did Neolithic Farming Fail? The Case for a Bronze Age Agricultural Revolution in the British Isles». Antiquity 86: 707-722. 